\title{
Um caso particular: diálogo ou entrevista?
}

A particular case: dialogue or interview?

Luiz Antônio da Silva

Universidade de São Paulo - USP

DOI: https://doi.org/10.5902/2176148538823

Resumo: No início dos estudos sobre Análise da Conversação, na década de 1980, o diálogo, seguindo as trocas propostas por Sacks, Schegloff e Jefferson (1974), do tipo ababab, é considerado como o modelo prototípico da oralidade. Prosseguindo os trabalhos sobre conversação, foi possível perceber que tal classificação não é tão simples assim. Parece que, quanto mais aumenta o número de participantes, mais complexo se torna a descrição do processo. Este trabalho tem por objetivo estudar o Inquérito 396, do Projeto NURC/ SP, rotulado como D2, isto é, diálogo entre dois informantes. Seguindo os modernos estudos sobre interação, foi possível chegar à conclusão que não se trata de um simples diálogo entre dois informantes, mas que as características que envolvem os interactantes derivam para outras características paralelas, não esperadas em uma simples gravação para compor o corpus do Projeto NURC/SP. Fundamentados em Goffman (1981) e KerbratOrecchini (1995), foi possível explicar a complexidade deste particular inquérito.

Palavras-chave: Interação. Oralidade. Conversação. Diálogo. Papéis conversacionais.

Abstract: At the beginning of the studies on Conversational Analysis, in the 1980's, dialogue, following the turn-taking proposed by Sacks, Schegloff and Jefferson (1974), the ababab type, is considered as the prototypical sample of orality. Continuing the work on conversation, it was possible to realize that such classification is not so simple. It seems that the more the number of participants increases, the more complex the description of the process becomes. This study aims to study the Survey 396, part of the NURC / SP Project, labeled D2, that is, a dialogue between two informants. Following the modern studies on interaction, it was possible to conclude that it is not a simple dialogue between two informants, because the characteristics that involve the interacting derive to other parallel characteristics, not expected in a simple recording of the NURC / SP Project. Based on Goffman (1981) and Kerbrat-Orecchini (1995), it was possible to explain the complexity of this particular investigation.

Keywords: Interaction. Orality. Conversation. Dialogue. Conversational roles. 
Luiz Antônio da Silva

\section{Considerações Iniciais}

No Brasil, a década de 1980 assistiu à entrada dos estudos sobre Análise da Conversação, introduzidos, de fato, por Luiz Antônio Marcuschi depois de um período de pós-doutorado na Alemanha. Depois de apresentar uma rica bibliografia sobre a área de estudos e inovar com modernas convenções sobre transcrição de língua falada, tais estudos desenvolveram bastante, especialmente entre os pesquisadores do Projeto NURC/ SP, sediados na Universidade de São Paulo.

Conceitos mais claros sobre interação, conversação e oralidade começaram a ser debatidos e fundamentados em estudos científicos no Brasil. Com isso, os trabalhos fundamentados nos corpora do Projeto NURC/BR tomaram novos rumos, deixando de lado os antigos modelos calcados na dicotomia fala/escrita.

O corpus do Projeto NURC/BR está dividido em três gêneros: EF (Elocuções Formais, isto é, aulas e conferências universitárias); DID (Diálogo entre dois informantes, isto é, entrevistas feitas por um Documentador e um Informante) e D2 (Diálogo entre dois informantes, em que dois interlocutores conversam a respeito de temas orientados por um documentador).

É possível, no entanto, perceber que alguns inquéritos fogem a essa formatação e adquirem contornos diferentes e de difícil classificação. É o caso do Inquérito 396, do NURC/SP, constante em Castilho e Preti (1987).

Nosso objetivo é esclarecer e justificar alguns contornos deste Inquérito que fogem à regra e adquirem novas e complexas características e que são de difícil classificação, considerando os três gêneros propostos no Projeto NURC/BR. Ainda que saibamos que a época atual é frutífera em estudos teóricos sobre gêneros, em particular sobre gêneros orais, não será objetivo deste trabalho uma discussão mais pormenorizada a respeito do assunto.

Para isso, a fundamentação teórica segue as orientações de Goffman (1981) e Kerbrat-Orecchini (1995).

\section{Os interactantes da conversação}

No Brasil, a equipe do Projeto NURC/SP, coordenada pelo Prof. Dr. Dino Preti, juntamente com os pesquisadores ligados ao Prof. Dr. Luiz Antônio Marcuschi, da Universidade Federal de Pernambuco, foram responsáveis pelos estudos situados na área de Análise da Conversação. Os diversos trabalhos teóricos enfrentaram a difícil tarefa de conceituar o termo conversação. Para Marcuschi (1988, p. 319-320), conversação é 
entendida "como uma interação centrada da qual participam pelo menos dois interlocutores que se revezam, tomando cada qual pelo menos uma vez a palavra, dando-se o evento comunicativo em uma identidade temporal". No mesmo estudo, Marcuschi (1988, p. 322) esclarece que o termo conversação pode ser tomado em sentido amplo, abrangendo todas as formas de interação: "entre médicos e pacientes, no tribunal, em sessões de terapia, na escola, nos aconselhamentos, nas entrevistas, na interação intercultural, interétnica".

Fundamentados em Vigara Tauste (2000), Leite et alii (2010) fazem considerações importantes sobre a conversação:

Um caso

particular

Fávero et al. (2010, p. 93) afirmam que a conversação é "um processo interacional específico, que implica participação conjunta dos interactantes na dinâmica evolutiva de um evento comunicativo informal, localmente processado". Hilgert (2001, p. 65) salienta que o texto conversacional caracteriza-se por ser processo e não produto, isto é, o texto falado, propriamente dito, constitui-se no próprio ato de produção. Dessa forma, o planejamento do que dizer e a formulação desse dizer não são etapas que se sucedem, mas são simultâneas, por isso mesmo são frequentes as descontinuidades, pois o fluxo da informação não ocorre de forma fluente e continuada. Com isso, são comuns hesitações, segmentos cortados, reformulações, silêncios, marcadores conversacionais, sobreposição de vozes.

Outra dificuldade encontrada pelos estudiosos foi conceituar os papéis conversacionais: falante e ouvinte. À primeira vista, não há grandes dificuldades, pois falante é aquele que fala e ouvinte é aquele que 
Luiz Antônio da Silva ouve. Não é, entretanto, tão simples assim, já que é possível encontrar um falante que ouve e um ouvinte que fala. Dessa forma, vários estudos abordaram essa questão.

Goffman (1981) defende a necessidade de se reanalisar os conceitos originais do modelo diádico falante/ouvinte, uma vez que tais conceitos encobrem uma série de aspectos da identidade social, relevantes para a análise da interação face a face. Os interactantes de um evento interacional desempenham papéis comunicativos e de identidade, de forma que falante e ouvinte assumem papéis diversos durante a interação.

As questões referentes ao ouvinte abrangem a estrutura de participação e as referentes ao falante, formatos de produção.

No plano do ouvinte, identificam-se diversas maneiras de ouvir e envolvem dois tipos de participação: ouvintes ratificados e ouvintes não-ratificados. Os primeiros são reconhecidos como indivíduos que fazem parte da interação em curso; os segundos são reconhecidos como indivíduos que não participam diretamente da interação. O primeiro tipo - ouvintes ratificados - abrange três estatus de participação: ouvinte endereçado; ouvinte não-endereçado; plateia. $\mathrm{O}$ primeiro refere-se a alguém a quem o falante dirige sua atenção visual, isto é, o ouvinte a quem a fala é dirigida especificamente. $\mathrm{O}$ ouvinte não-endereçado remete àqueles a quem a fala não é dirigida especificamente, mas tem estatus participativo. A plateia ou audiência remete-nos a um conjunto de ouvintes ratificados na interação que ocorre em contextos institucionais, isto é, há um falante que se dirige a vários ouvintes e a função deles é apreciar as observações feitas e não responder de forma direta, ainda que possam fazê-lo. O segundo tipo - participantes não-ratificados - remete-nos àqueles ouvintes que não são reconhecidos como participantes diretos da interação. Podemos falar em ouvinte inadvertente, isto é, aquele que participa ocasionalmente da conversação e um ouvinte subreptício, aquele que participa sem que o falante saiba, como, por exemplo, nas escutas telefônicas.

No plano do falante - formatos de produção - Goffmann distingue os seguintes papéis comunicativos: animador; autor; principal. o primeiro refere-se ao falante enquanto responsável pela atividade física, acústica da fala, uma espécie de "máquina de falar". o segundo é o falante visto como agente, o "dono do script", responsável pelo conteúdo e implicações da fala. 0 terceiro - principal - representa o falante visto como indivíduo revestido de uma posição estabelecida pela fala que produz; o falante representa um indivíduo com identidade social particular, com 
capacidade específica enquanto membro representante de um grupo; alguém que está comprometido com o que as palavras expressam.

Aplicados ao corpus deste trabalho, tais noções ajudam a definir os papéis dos participantes do Inquérito 396. Há momentos em que a Documentadora exerce o papel de animador, pois está ali para representar o Projeto NURC, estimulando os informantes a falarem. Segundo o que se pode apurar nas orientações da Coordenação do NURC, em nenhum momento, no formato D2, a Documentadora deveria exercer a função de autor. Quando os dois informantes conversam, a Documentadora deveria exercer a função de plateia ou, em alguns momentos, de ouvinte não-endereçado.

Também, recorremos ao recorte teórico de Kerbrat-Orecchioni (1995), em que o termo diálogo é reservado ao sentido etimológico(dia: por meio de; logos: palavra) e dílogo refere-se à troca diádica (dois par-

Um caso particular ticipantes no diálogo), enquanto trílogo refere-se a trocas em que há três participantes. No Inquérito 396, espera-se que haja dílogo quando há trocas entre os dois informantes ou entre um dos informantes e a Documentadora. Espera-se que haja trílogo quando a Documentadora se dirigir, indistintamente, aos dois informantes.

Fávero e Aquino (2003) asseveram:

\footnotetext{
Se no dílogo o locutor L2 só pode intervir após o locutor L1, sendo a interrupção com sobreposição a única "fantasia" possível, no trílogo, a fórmula ababab de Sacks, Schegloff e Jefferson (op. cit.) não se aplica; nele não há regras fixas, nem seleção prévia do sucessor e o locutor L3 pode tomar a palavra sem que esta lhe seja dirigida (FÁVERO e AQUINO, 2003, p.160).
}

\section{Corpus}

Atualmente, no meio acadêmico brasileiro, tem havido uma profunda discussão a respeito de gêneros, notadamente a respeito dos gêneros orais. Travaglia et al. (2013) apresentam um conceito de gêneros orais.

Em suas discussões o PETEDI estabeleceu que gênero oral é aquele que tem como suporte a voz humana (vista como a característica particular que tem o som produzido pelo aparelho fonador) e que foi produzido para ser realizado oralmente, utilizando-se a voz humana, independentemente de ter ou não uma versão escrita. (...) Por isto é importante para considerar o gênero como oral tanto que ele tenha como suporte a voz humana, quanto que tenha sido produzido por dada co- 
Luiz Antônio

da Silva

munidade para ter uma realização oral. 0 suporte do gênero oral não pode ser visto como a fala, porque esta é a própria língua usada oralmente. Evidentemente os gêneros orais são construídos com a língua falada e terão características dessa que podem ser específicas de um gênero ou meramente da língua falada e comuns a todos os gêneros orais (TRAVAGLIA et al., 2013, p.4-5).

Ainda que se reconheça a importância da discussão a respeito do assunto, neste estudo, não haverá a preocupação com tal discussão, pois o escopo básico abrange o que já está definido nos corpora do Projeto NURC/BR: três tipos de gênero: Elocuções Formais (EF); Diálogo entre documentador e informante (DID); Diálogo entre dois informantes (D2).

O corpus do trabalho é composto por um inquérito do Projeto NURC/SP, 396, do tipo D2, isto é, diálogo entre dois informantes, constante em Castilho e Preti (1987, p. 234-233). A gravação tem 75 minutos de gravação, discorrendo sobre dois temas centrais: vestuário e diversões. O informante L1 é do gênero masculino, com 81 anos, viúvo, dentista. A informante L2 é do gênero feminino, com 85 anos de idade, viúva, professora. Há um alto grau de envolvimento entre eles, pois são irmãos. O inquérito foi gravado no dia 19 de novembro de 1976. A Documentadora é mulher e jovem (cerca de 25 anos).

Para a transcrição, seguem-se as normas estabelecidas pelo Projeto NURC/SP, constante em Castilho e Preti (1987, p. 9), descritas a seguir.

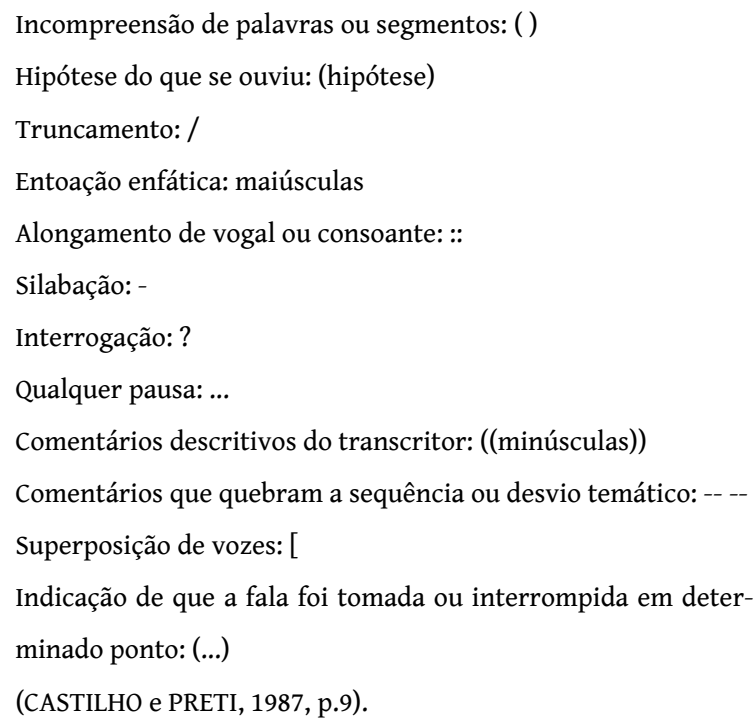


Para marcar os exemplos foi adotada a seguinte notação: NURC/ SP, Inquérito 396, e a página onde se encontra o fragmento. Foram colocadas em negrito as intervenções em destaque.

A coordenação do Projeto NURC orientava todos os documentadores como conduzir a gravação: lançar a pergunta inicial, a fim de que os informantes conversassem espontaneamente.

\section{EXEMPLO 1:}

Doc. Olha gente eu queria que vocês comenta::ssem... como é que era o vês/ vestuá::rio... da época de vocês... de mocinho... das diversas classes sociais...

L1: sociais...

Doc. certo?

Um caso

particular

L1: certo... então...

L2: (pra/) quando era ir pra escola tinha uniforme...

(NURC/SP, Inquérito 396, p.179)

Trata-se do início do inquérito. Na primeira intervenção, a Documentadora precisa direcionar a conversa e cumprir seu papel de estimular a conversa entre os dois informantes. Como já foi mencionado, vestuário é um dos temas relacionados neste inquérito. É importante salientar que havia uma distribuição de temas, conforme as faixas etárias e conforme o gênero dos informantes. Neste caso, a Documentadora exerce sua função, dirigindo a L1 e L2, como se fosse uma entrevista. Não houve escolha de um interlocutor específico para começar a desenvolver o tema lançado. Sendo assim, L1 ou L2 poderá assumir a palavra. Percebe-se que os informantes não estão muito à vontade, há hesitação da parte de L1, por isso L2 inicia o relato a respeito do vestuário. Não se espera, contudo, que os informantes, ou um dos informantes, responda, secamente, ao que foi perguntado pela Documentadora. Não se espera que o formato entrevista continue, mas que o inquérito assuma o formato de diálogo, ou, como diz Kerbrat-Orecchioni (1995), dílogo. A partir do instante em que os informantes começam a conversar, espera-se que a Documentadora assuma a função de plateia.

Outra função do documentador era intervir quando houvesse desvio do tema, como se percebe no exemplo a seguir. 


\section{EXEMPLO 2}

L2 e porque muitos comendadores

L1 remediadas...

L2 compravam títulos né?...

L1 é::: eram remediadas...

\section{[}

L2 compravam títulos:: eu sabia tal comendador fulano... como é?... é a

Luiz Antônio

da Silva

família que comprava título o::: Matarazzo também é comendador o outro não é?

Doc. uhn uhn

L1 mas::

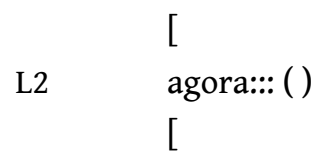

Doc. agora vocês Acham que os:: tecidos - voltando ao... ao assunto - éh::

os tecidos se adaptavam eram adequados ao nosso clima... naquela época?

(NURC/SP, Inquérito 396, p.193-194)

O tema em questão era vestuário, mas os dois informantes acabam se desviando do tema. Dessa forma a documentadora intervém para reorientar a conversa, de acordo com o tema proposto, vestuário e não títulos nobiliárquicos.

Nos inquéritos do tipo D2, o documentador deveria ficar atento à participação dos dois informantes, pois era necessário que houvesse participação equilibrada. Caso um dos informantes tivesse participação tímida, caberia ao documentador motivar o interlocutor que pouco participasse.

\section{EXEMPLO 3}

Doc. e a dona A. a senhora lembra de alguma toaLEte... muito bonita que a senhora tenha gosta::do do que tenha ficado... na memória?

(NURC/SP, Inquérito 396, p.188) 
Neste caso, como a Documentadora percebe que L1 está dominando a cena conversacional, faz uma pergunta à L2, a fim de obter informações sobre a toalete feminina e, também, dar oportunidade para que ela participe da conversação.

Também, era possível a interferência do documentador quando julgasse que algo que um dos informantes dissesse era interessante e julgasse necessário explorar.

\section{EXEMPLO 4}

L1 mas agora geralmente estão comprando... roupas FEItas::

Doc. é isso que eu perguntar:: naquela época não havi::a...

L1 existia para homens existia aqui o Bom Diable

(NURC/SP, Inquérito 396, p.200)

Um caso

particular

Os informantes estão contando a respeito do vestuário da época deles e deixam claro que era comum comprar roupas sob encomenda, no entanto L1 assevera que, na época em que o inquérito foi gravado, é mais comum comprar roupas feitas. A documentadora intervém para pedir esclarecimento a respeito de uma curiosidade: na época dos informantes não havia compra de roupas feitas? L1 esclarece que já havia roupas feitas para homens.

Em síntese, a função do documentador não era participar da conversa, pelo contrário, deveria participar pouco, apenas, nos momentos necessários. Assim, o que não se espera é que os informantes, ou um desses informantes, responda, secamente, à pergunta para o Documentador. Não se espera que o formato entrevista continue e sim que adquira o formato DIÁLOGO ou como diz Kerbrat-Orecchioni (1995), dílogo e, com três participantes, trílogo.

\section{Diálogo ou entrevista? Dílogo ou trílogo?}

Considerando o formato estabelecido pelo Projeto NURC/SP, são possíveis três tipos de esquema:

$$
\begin{aligned}
& \text { Documentadora - L1 ou L2 } \\
& \text { Documentadora - L1 } \\
& \text { Documentadora - L2 } \\
& \text { L1 - L2 } \\
& \text { Documentadora - L1 + L2 }
\end{aligned}
$$


Luiz Antônio da Silva

Os três primeiros referem-se a participações esporádicas da Documentadora. O primeiro engloba a primeira intervenção ou alguma pergunta dirigida, indistintamente, a um dos dois informantes. O segundo e o terceiro esquema refere-se a intervenções da Documentadora com o intuito de orientar ou redirecionar a conversa. Nesses casos, a intervenção pode ser direcionado a um ou a outro informante. $O$ quarto esquema é o núcleo central do Diálogo entre dois informantes (D2), pois aborda a conversa entre L1 e L2 sobre os temas lançados, previamente, pela Documentadora, no entanto o Inquérito 396 apresenta algumas características peculiares, pois a Documentadora deixa de exercer sua função preliminar e passa a ser mais um dos interlocutores. Inúmeras intervenções da Documentadora não a colocam como entrevistadora, mas como participante ativa da conversa. Isso ocorre, especialmente porque os informantes se unem para falar a respeito da época em que eles viveram (pelo menos, uma geração anterior à geração da Documentadora.), buscando mostrar que tudo da época deles era melhor do que o presente que, na verdade, é a época da Documentadora (jovem).

\section{EXEMPLO 5}

L1: aquela rapaziadinha já quis começar a usar... calça comprida...

\section{Doc.: uhn}

L1: e:: um chapeuzinho diferente lá:: já queria... (já não)... já queriam ser... MOço...

\section{Doc.: uhn}

L2: é:: sim... tanto que meu filho mais vê;;lho.. e eu com/compramos um terninho de::...

\section{[}

L1 os costumes foram...

L2: de calça comprida....

Doc.: uhn uhn...

L2: e ele estava no ginásio Oswaldo Cruz...

Doc.: uhn uhn

(NURC/SP, Inquérito 396, p.219)

Neste fragmento, percebe-se, claramente, que a Documentadora não desempenha, simplesmente, seu papel de mediadora do diálogo. As diversas intervenções, marcadas em negrito, constituem turnos inseridos interacionais (Galembeck, Silva e Rosa, 1990, p.88). Significa 
dizer que a Documentadora exerce a função de interlocutora, pois são turnos de ouvinte e não de alguém que esteja na plateia. Para que a Documentadora participe, provavelmente, a mirada de olhos está na direção dela. A grande preocupação é se ela está entendendo ou não os diferentes costumes da época dos informantes.

É importante salientar que, em todo o inquérito 396, foram encontrados 129 turnos inseridos interacionais, que, em geral, indicam entendimento, assentimento, concordância da parte da Documentadora. Considerando os demais inquéritos, nenhum outro apresenta essa característica. Como exemplo, o Inquérito 343, com 80 minutos de gravação, apresenta 25 intervenções do documentador e, apenas, 3 turnos inseridos interacionais.

Um caso

particular

\section{EXEMPLO 6}

L1: São Paulo era mais FRIo do que hoje... bem mais frio a não ser um dia:: este ano tivemos frio mas... raramente é... São Paulo era era:: -- como a senhora sabe - era São Paulo da garoa...

\section{Doc.: uhn uhn}

\section{[}

L1: São Paulo frio... então:: era:: era:: era:: e:: exigia-se uma toalete mais... mais:: pesada um bocadinho

(NURC/SP, Inquérito 396, p.194)

Este exemplo reforça a observação feita anteriormente: tanto L1 quanto L2 preocupam-se em produzir seus turnos voltados para a Documentadora. Neste caso, não foi, apenas, uma possível mirada de olhos, mas, discursivamente, a Documentadora é chamada a participar: "como a senhora sabe".

\section{EXEMPLO 7}

L1: usava um corpinho... não era... não era este:: negócio que hoje tem - - como é que chama?--... hoje é::... esse negócio que se prende aqui...

Doc.: sutiã?... ahn

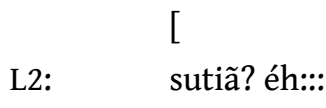

[

L1: $\quad$ SUtiã...

(NURC/SP, Inquérito 396, p.189) 
Este exemplo reforça as observações anteriores e deixa evidente que a Documentadora não desempenha a função nem de ouvinte não-endereçado, isto é, alguém que se encontra na cena enunciativa, mas não participa da conversa; igualmente, não desempenha a função de plateia, isto é, um mero espectador da conversa. A Documentadora participa, ativamente, da conversa, a ponto de responder a uma dúvida de L1, que não encontra o termo "sutiã". Na verdade, caso não fosse um inquérito singular, quem deveria enunciar tal segmento seria L2, interlocutor direto de L1.

Luiz Antônio

da Silva

\section{EXEMPLO 8}

L2: lá no Colégio Florence eu era menina... eu tinha eu acho que uns sete oito anos eu ti/ acho que uns oito anos... minha irmã é que era:: mais velha que eu... mas LÁ

L1:

[

mas...

L2: não havia mais liberdade...

Doc.: orientação alemã né? ela nos falou é umaorientação alemã [

L2: $\quad$ ahn? é:: é sim alemã...

(NURC/SP, Inquérito 396, p.191)

Aqui, mais um exemplo que comprova que a Documentadora não exerce sua função precípua de, apenas, orientar e reorientar a conversa. Para demonstrar que ela desempenha a função de um locutor, tal como L1 e L2, repare-se que a interferência “orientação alemã né?" nada mais é que um turno inserido interaciona (GALEMBECK, SILVA \& ROSA, 1990), cuja função é, apenas, resumir o que foi dito por L2. Trata-se de um turno de ouvinte que participa, ativamente, da cena conversacional.

\section{EXEMPLO 9}

L1: era bem apertadinha bem:: apertada na manga então diziam quem... malandro é que usava a roupa canudo de pito para esconder a navalha ali dentro...

Doc.: ah é?

L1: ((riu))

(NURC/SP, Inquérito 396, p.203) 
Neste exemplo, L1 conta que, na época dele, havia um tipo de roupa que era chamado "canudo de pito" e explica que a manga era apertada para que o malandro escondesse a navalha, caso precisasse usar. Como o costume é estranho à Documentadora, ela manifesta sua admiração, por meio de um turno inserido interacional de surpresa "ah é?". Isso é prova evidente que L1 conta o caso não para L2, como deveria ser um D2 comum, mas para a Documentadora. Com isso, é possível perceber que o esquema conversacional é: L1 + L2 -Documentadora.

\section{EXEMPLO 10}

L1: foi bárbara foi medo:: tinha a gripe... éh::: as pessoas eram::... até:: enterradas até semi-vivas... alguns semi-vivas... e diziam então que nos hospitais eram tan::to tanto tanto tanto que dava-se o chá da meia-noite... ((risos da Documentadora)) ouviu falar do chá da meia-noite?

Doc.: ouvi falar esse termo

(NURC/SP, Inquérito 396, p.203)

L1 relata um caso bastante trágico que houve em São Paulo, por ocasião de uma epidemia de gripe. Muitas pessoas morreram e L1, ao relatar o caso, de forma emocionada, cita um termo próprio da época: "chá da meia-noite". Como tem dúvidas se a Documentadora conhece tal termo, imediatamente, pergunta: "ouviu falar do chá da meia-noite?". Preti (1991) lembra que, no Inquérito 396, é muito comum intervenções dirigidas à Documentadora, com a finalidade de saber se havia ou não conhecimento de certos vocábulos ou expressões antigas.

\section{EXEMPLO 11}

L1: Hoje o ordenado de uma professora é uma miséria... uma professora ganhava... ganhava... ganhava... - já disse à senhora - trezentos trezentos e cinquenta... um delegado ganhava quatrocentos um juiz ganhava quinhentos... hoje uma professora ganha::... Doc.: pouquíssimo não é?

(NURC/SP, Inquérito 396, p.208)

L1 está discorrendo a respeito das mudanças salariais havidas na classe do magistério. Assevera que, no tempo dele, o salário de uma professora era equiparado ao salário de um delegado e de um juiz. No final 
do turno de L1, este suspende sua fala e hesita, contudo a Documentadora completa o segmento que seria enunciado por L1, constituindo o que Preti (1986) chama de "sintaxe a dois", pois o segmento enunciado por L1 é completado, não apenas no nível semântico, mas também no nível sintático, formando um único enunciado, sintaticamente falando.

\section{EXEMPLO 12}

L1: as casimiras também eram todas importadas... e:: o veludo astracã seda milinó...

Luiz Antônio da Silva

\section{Doc.: o que é isso? ((ri))}

L1: milinó é milinó é uma lã.

(NURC/SP, Inquérito 396, p.198)

Neste último exemplo, mais uma vez, fica evidente o estatus conversacional da Documentadora. Como L1 e L2 estão relatando os costumes da época deles, idosos, diferente da época da Documentadora, jovem, aparece um termo que a Documentadora desconhece: "seda milinó". Imediatamente, a Documentadora, como se fosse um dos informantes, intervém e pergunta o que significava aquele termo.

\section{Considerações Finais}

O objetivo precípuo deste trabalho foi tecer considerações a respeito da estrutura da cena conversacional em um inquérito do Projeto NURC/SP, do tipo D2, diálogo entre dois informantes. Pelas características do inquérito, a Documentadora deveria intervir no início, apresentando o tema a ser explorado e, esporadicamente, orientar e/ou reorientar a conversa, deixando a cargo de L1 e L2 a conversa propriamente dita, configurando o esquema L1 - L2, como se fosse um dílogo (KERBRAT-ORECCHIONI). Dessa forma, ora L1 ora L2 acabariam exercendo a função de ouvinte endereçado, enquanto a Documentadora exerceria a função de ouvinte não-endereçado (GOFFMANN, 1981).

A singularidade do Inquérito 396 reside no fato de a Documentadora tornar-se mais um participante da conversa. Poderíamos pensar em um trílogo (KERBRAT-ORECCHINI), mas, na verdade, o que ocorre não é uma conversação com três participantes com igual estatus, configurando o esquema L1 + L2 - Documentadora. Em todo o momento, L1 + L2 se unem com a finalidade de provar que os costumes da época deles era melhor do que os costumes atuais, próprios da Documentadora, que é jovem. Sendo assim, não há, propriamente, a figura do ouvinte não-endereçado. 
Preti (1991) contempla uma importante informação a respeito do inquérito estudado:

O inquérito 396-D2 é um diálogo entre dois informantes de sexo diferente, ele com 81 anos de idade, ela com 85, sobre o tema vestuário e diversões. Normalmente, nesse tipo de inquérito, as intervenções do documentador devem ser mínimas. Acontece, porém, que essa situação de criar um diálogo na presença de um estranho parece não ter sido bem aceita pelos dois idosos, de tal maneira que eles ficam sempre na dependência Um caso da entrevistadora, das suas propostas, das suas intervenções, para depois dialogarem, suprindo mutuamente as eventuais deficiências das respostas. Quer dizer, a fala de ambos é norparticular malmente dirigida à documentadora e só excepcionalmente é que o inquérito se torna um diálogo entre dois informantes. Em geral, ele se revela uma conversação a três. Essa característica torna-se essencial na compreensão, por exemplo, do problema da fluência desse "discurso a dois" dirigido a um terceiro e explica o número limitado (ou contido) de tópicos ou subtópicos novos, em virtude do encaminhamento do tema pela documentadora (PRETI, 1991, p.17-18).

Em outras palavras, o Inquérito 396 se caracteriza por um tipo de diálogo muito mais voltado para esclarecer os problemas suscitados pela Documentadora do que, propriamente, para uma interação natural entre L1 e L2.

\section{REFERÊNCIAS}

CASTILHO, Ataliba T. de; PRETI, Dino (Orgs.). A linguagem falada culta na cidade de São Paulo. São Paulo: T.A.Queiroz/Fapesp, vol. II - Diálogos entre dois informantes, 1987.

FÁVERO, Leonor L.; AQUINO, Zilda G. O. A dinâmica das interações verbais: o trílogo. In: PRETI, Dino (Org.). Interação na fala e na escrita. 2. ed., São Paulo: Humanitas, p.159-177, 2003. 
FÁVERO, Leonor L. et al.. Interação em diferentes contextos. In: BENTES, Ana C.; LEITE, Marli Q. (Orgs.). Linguística de texto e análise da conversação: panorama das pesquisas no Brasil. São Paulo: Cortez Editora, p.91-158, 2010.

GALEMBECK, Paulo de T.; SILVA, Luiz Antônio; ROSA, Margaret de Miranda. O turno conversacional. In: PRETI, Dino; URBANO, Hudinilson (Orgs.). A linguagem falada culta na cidade de São Paulo. São Paulo: Fapesp/T.A.Queiroz, vol.IV- Estudos, p.58-98, 1990.

Luiz Antônio da Silva GOFFMAN, Erving. Forms of talk. Filadélfia: Universidade da Pensilvânia, 1981.

HILGERT, José G. A qualificação discursiva no texto falado. In: HURBANO, Hudinilson et al.(Orgs.). Dino Preti e seus temas: oralidade, literatura, mídia e ensino. São Paulo: Cortez Editora, p.62-84, 2001.

KERBRAT-ORECCHIONI, Cathérine. Introdução. In: KERBRAT-ORECCHIONI, C.; PLANTIN, Christian (Orgs.). Le trilogue. Lyon: Universidade de Lyon 2, p.2-28, 1995.

LEITE, Marli Q. et el.. A Análise da Conversação no Grupo de Trabalho Linguística do Texto e Análise da Conversação da Associação Nacional de Pós-Graduação em Letras e Linguística. In: BENTES, Ana C.; LEITE, Marli Q. (Orgs.). Linguística de texto e análise da conversação: panorama das pesquisas no Brasil. São Paulo: Cortez Editora, p.49-87, 2010.

MARCUSCHI, Luiz Antônio. Questões atuais na Análise da Conversação. Encontro Nacional da ANPOLL. Recife: ANPOLL, p.319-335, 1988.

PRETI, Dino. Sobre a tensão conversacional. Tradução \& Comunicação,São Paulo, n.8, p. 27-40, 1986.

PRETI, Dino. A linguagem dos idosos. São Paulo:Contexto, 1991.

SACKS, Harvey; SCHEGLOFF, Erving; JEFFERSON, Gail. A simplest systematics for the organization of turn-taking for conversation. Language, n.50, p.696-735, 1974. 
TRAVAGLIA Luiz Carlos et. al.. Gêneros orais- conceituação e caracterização. Anais do SILEL, Uberlândia: Editora da Universidade Federal de Uberlândia, vol.3, n.1, p. 1-8, 2013.

VIGARA TAUSTE, Ana M. Las relaciones de poder en La conversación. Revista Argentina de Linguística, n.16, p.175-211, 2000. 
